\title{
Power system restoration in distribution network using minimum spanning tree - Kruskal's algorithm
}

\author{
Hasmaini Mohamad, Wan Iqmal Faezy Wan Zalnidzham, Nur Ashida Salim, Shahrani Shahbudin, \\ Zuhaila Mat Yasin \\ Faculty of Electrical Engineering, Universiti Teknologi MARA, Malaysia
}

\begin{tabular}{|c|c|}
\hline Article Info & ABSTRACT \\
\hline Article history: & Events such as natural and manmade interference, line, transformer and \\
\hline Received Jan 4, 2019 & $\begin{array}{l}\text { feeder outages that occur in electric power distribution system negatively } \\
\text { impact the continuity of power supply, thus affecting the power demand }\end{array}$ \\
\hline Revised May 6, 2019 & supply as well as customer's satisfaction. In that cases, the restoration of \\
\hline Accepted May 27, 2019 & $\begin{array}{l}\text { power needs to be carried out immediately in order to guarantee the system's } \\
\text { reliability. The power flow path identification is considered as a difficult task }\end{array}$ \\
\hline Keywords: & $\begin{array}{l}\text { especially in a huge system due to large number of switches. Kruskal's } \\
\text { algorithm is presented in this paper to find the minimum power flow path in }\end{array}$ \\
\hline Graph theory & a power distribution network. The comparison of performance between \\
\hline Kruskal's algorithm & presented Kruskal's algorithm and Binary Particle Swarm Optimization \\
\hline Minimum spanning tree & $\begin{array}{l}\text { (BPSO) was made in solving a problem regarding network reconfiguration. } \\
\text { The proposed load restoration approach is tested on IEEE 33-bus single }\end{array}$ \\
\hline Power system restoration & $\begin{array}{l}\text { feeder radial distribution system using MATLAB software. From the results, } \\
\text { it is found that the presented Kruskal's algorithm was able to search for the } \\
\text { minimal power flow path that contribute to loss reduction for power } \\
\text { restoration after the occurrence of fault. }\end{array}$ \\
\hline
\end{tabular}

Copyright $\odot 2019$ Institute of Advanced Engineering and Science. All rights reserved.

\section{Corresponding Author:}

Hasmaini Mohamad,

Faculty of Electrical Engineering,

Universiti Teknologi MARA,

40450, Shah Alam, Selangor, Malaysia.

Email: hasmaini@uitm.edu.my

\section{INTRODUCTION}

Distribution network delivers the electric power to various type of loads by considering capacity issues and voltage tolerances to ensure there are no interruptions in the flow of power. An outage due to unavoidable faulted events degrades the functionality of the electrical distribution system, thus disrupting the continuity of power supplied to the electrical consumers. As for example, on 30 to 31st July 2012, the largest electrical outage in history that involved $50 \mathrm{GW}$ of load affected about 670 million people of northern India, which is around 9\% of the world population [1]. Unpredictable interruptions that occur in a distribution system may hinder the task to bring back the power system immediately to its healthy state. Therefore, service restoration by switching operation needs to be done immediately in the loss area to guarantee load demand is met [2-12].

The switching operation main objective is to reschedule the loads efficiently by proper switching of distribution power lines which consists of sectionalisation switches and tie switches [13]. This is done to reduce the influence of faults on customers as well as improving the reliability of the distribution network. Reconfiguring the feeders in the distribution network will redistribute the load more evenly, therefore reduce the voltage fluctuation, preserving the load balance and minimize losses. Nevertheless, the process of restoring power is a tough task because radiality of the network, voltage drop and current limits has to be 
maintained [14]. Hence, minimum spanning tree-based approach is presented to discover the best power flow path.

A minimum spanning tree (MST) is a subset of the edges of an undirected graph that connects all the vertices together, without producing cycles and with the minimum total edge weight. The algorithm such as Dijkstra, Kruskal, Prim and Reverse-delete are the classic algorithm of the minimum spanning tree. Network reconfiguration is determined by altering the switches status whether it is close or open. [15] was looking for the optimum network reconfiguration with power loss minimization for the paper objectives. [16] presents Dijkstra's algorithm for network deduction and identification for optimal configuration of the reduced network. Prim's algorithm is proposed in [17] to find the power flow path in distribution network after an outage. Metaheuristic algorithm named Genetic Algorithm was implemented in [18] to select optimal solution based on fitness algorithm function. A new algorithm which is RAY algorithm was proposed in [19] to produce a minimum weighted spanning tree of the given graph with no direction pointed. [20] presented network reconfiguration based on Binary Particle Swarm Optimization (BPSO) that maximize the loads being supplied while ensuring voltage regulation is not violated and minimum loss of power is achieved through switching maneuver. [21] dealt with Kruskal's algorithm to solve service restoration problem. The idea of this paper is to cover the unsupplied area by restoring that area as much as it can after an outage and by finding the minimum switching order for the operational network. However, the problem formulation does not consider the voltage constraint during the load restoration.

Therefore, this research introduces Kruskal's algorithm which include voltage limit as part of the technical constraint. The objectives of this paper are to find the minimal power flow path that contribute to minimum power loss during load restoration in distribution network by using Kruskal's algorithm. The performance of the presented algorithm with Binary Particle Swarm Optimization (BPSO) is evaluated by solving a problem of network reconfiguration on IEEE 33-bus single feeder test distribution network.

\section{PROBLEM FORMULATION}

\subsection{Graph Theory}

Graph theory can be used to solve power restoration problem. The buses and feeder in a network is known as vertex while the distribution line is known as edge. A graph is categorized into undirected graph and directed graph. A directed graph is a graph where all the edges in that graph are directed from one node to another. In contrast, an undirected graph is a graph where all the edges are bidirectional. The terms involved in the implementation of Kruskal's algorithm is shown in Table 1.

Table 1. Symbols in a Graph

Image
(A) $\begin{aligned} & \text { The connection line of node A and B is known as } \\ & \text { an edge. The graph is an undirected graph } \\ & \text { because there is no direction pointed to the node. } \\ & \text { An edge that has a weight of } 6 \text { being connected } \\ & \text { between node A and node B }\end{aligned}$

\subsection{Kruskal's Algorithm}

Kruskal's algorithm was discussed in 1956 [22]. It is one of the greedy algorithm in graph theory that finds a minimum spanning tree for a connected weighted graph. A minimum spanning tree (MST) is a subset of the edges of a connected, undirected graph that connects all the vertices together, without forming any cycles and with the minimum total edge weight [23]. Minimum spanning tree are divided into line-based MST algorithm and node- based MST algorithm. Kruskal's algorithm are classified under line-based MST algorithm. There are two conditions that must be fulfilled in Kruskal's algorithm [24], that are the line weight in a graph is sort in ascending order and an empty subgraph $\mathrm{T}$ is created. Table 2 shows a framework of Kruskal's algorithm. 
Table 2. Framework of Kruskal's Algorithm

Thedel example to implement Kruskal's algorithm.

\subsection{Load Restoration using Kruskal's Algorithm}

Figure 1 shows the flowchart to find the path with minimum weight from the feeder to loads. The power system restoration in this paper is tested on a single feeder network. Line impedance are assigned as weight since the proposed algorithm is a weighted graph [21].

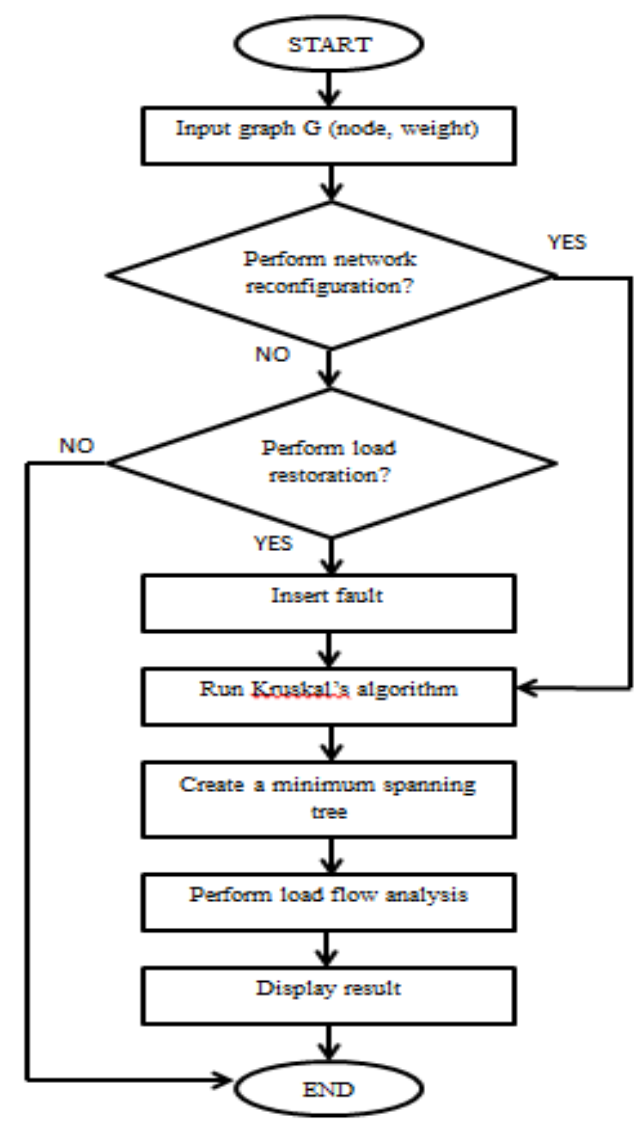

Figure 1. Flowchart of load restoration using Kruskal's Algorithm 
The input data consists of the buses and lines data of the test system network. There are two case studies in this research which are network reconfiguration and power restoration. The requirement to run either one of the case studies in Kruskal's algorithm is decided based on the presence of fault in the system.

In order to perform power restoration, fault must be injected by increasing the weight of the line which refers to the impedances of the lines. Higher weight means higher impedances which indicate fault in the system [25]. Then the process will continue by implementing Kruskal's to get a minimum weight spanning tree. In Kruskal, the edge will be sorted in ascending order based on the line impedance. This algorithm will highlight the edge of the graph starting from the edge that has the least weight until it gains a minimum total edge weight as long as it does not form any cycle. For final result, load flow was performed from the minimum weight spanning tree obtained. Result achieved from the Kruskal's algorithm is then analysed in the form of table and graph.

\subsection{Test Network}

The IEEE 33-bus single feeder distribution system, $12.66 \mathrm{kV}$ and $10 \mathrm{MVA}$, as shown in Figure 2 is used as the test system for this research. There are a total of 37 branches, 33 buses, 32 close switches and 5 open switches in the network. Branches S1-S32 indicate the sectionalizing switches while S33-S37 indicate the tie-line switches. The total of active and reactive load demand for this network is $3.715 \mathrm{MW}$ and 2.295MVar. The amount of active power loss and reactive power loss is $0.2024 \mathrm{MW}$ and $0.1349 \mathrm{MVar}$ respectively. Figure 3 shows the test network graph executed in MATLAB software.

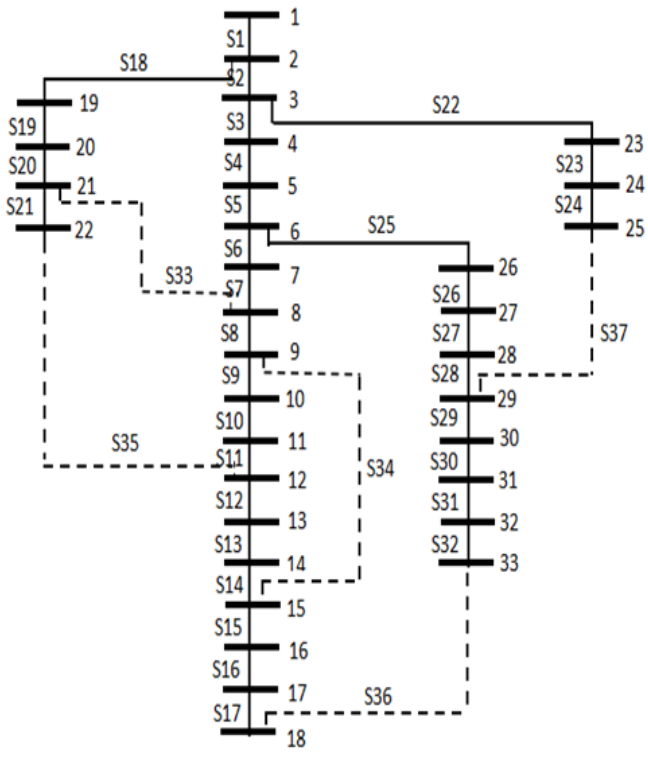

Figure 2. IEEE 33-bus single feeder system

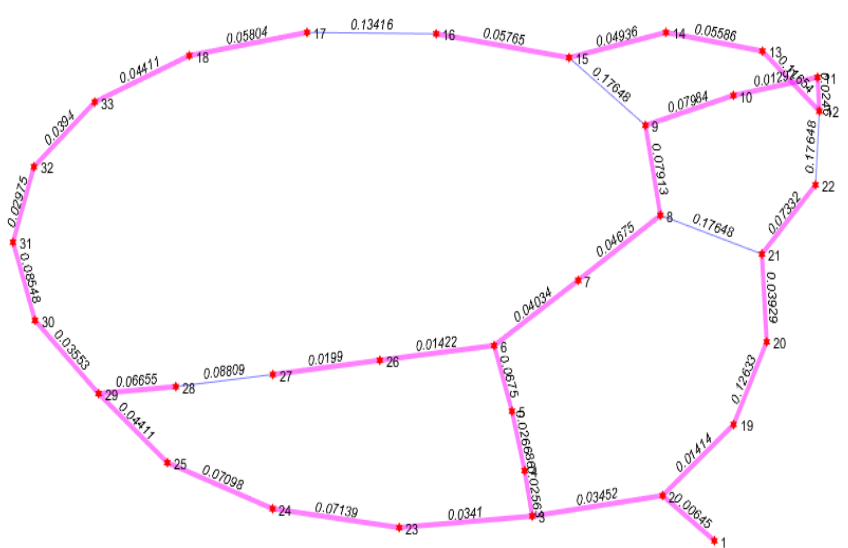

Figure 3. Test system in MATLAB

\section{RESULTS AND ANALYSIS}

Table 3 indicates the performance of the proposed Kruskal's algorithm with Binary Particle Swarm Optimization (BPSO). The minimization of power loss in a network is obtained by reconfiguring the network. At the same time, it also helps in improving the voltage profile and increases the system's reliability. After implementing this algorithm, the new set of open switches are S16, S27, S33, S34 and S35, while S7, S9, S14, S32 and S37 are the open switches selected by BPSO. From the result obtained, it is observed that both active and reactive power loss of the network using the proposed algorithm for the condition without fault are smaller than the base case. Kruskal's algorithm reduces the losses from $202.4 \mathrm{~kW}$ to $178.6 \mathrm{~kW}$ saving $23.8 \mathrm{~kW}$. The real and reactive power loss for BPSO are lesser compared to proposed Kruskal algorithm. In terms of time duration, the time taken to reconfigure the network using Kruskal's algorithm is $0.8571 \mathrm{~s}$ which is significantly lesser than BPSO that take 34.6300s. It is important to restore the unsupplied load quickly to maintain the system frequency. So, the implementation of Kruskal's algorithm in power distribution problem is one of the best way in reconfiguring the network for power restoration.

The acceptable voltage range in this test distribution network is between 0.9 pu to $1.00 \mathrm{pu}$. Figure 4 shows the results of voltage of the whole network using the proposed methodology was improved compared 
to base case voltage. The voltage profile in the figure reflects the lowest voltage across bus 18 as it is located at the very end of the feeder. The voltage at bus 18 shows an improvement from base case to Kruskal algorithm which is $0.9131 \mathrm{pu}$ to $0.9248 \mathrm{pu}$. However, the voltage when applying BPSO method are better compared to Kruskal. It is proven that power loss is smaller with the increase of voltage and thus increasing the efficiency of the network. The voltage for both methods are still in the limit range between $0.90 \mathrm{pu}$ and $1.00 \mathrm{pu}$.

Table 3. Result for Network Reconfiguration

\begin{tabular}{llccc}
\hline Algorithm & & Base case & Kruskal & BPSO \\
\hline Tie switches & & S33,S34,S35,S36,S37 & S16,S27,S33,S34,S35 & S7,S9,S14,S32,S37 \\
Load & P (MW) & 3.715 & 3.715 & 3.715 \\
& Q (MVar) & 2.295 & 2.295 & 2.295 \\
Generation & P (MW) & 3.916 & 3.893 & 3.854 \\
& Q (MVar) & 2.429 & 2.416 & 2.397 \\
Ploss (MW) & & 0.2024 & 0.1786 & 0.1393 \\
Qloss (MVar) & & 0.1349 & 0.1218 & 0.1022 \\
Time (s) & - & 0.8566 & 34.6300 \\
\hline
\end{tabular}

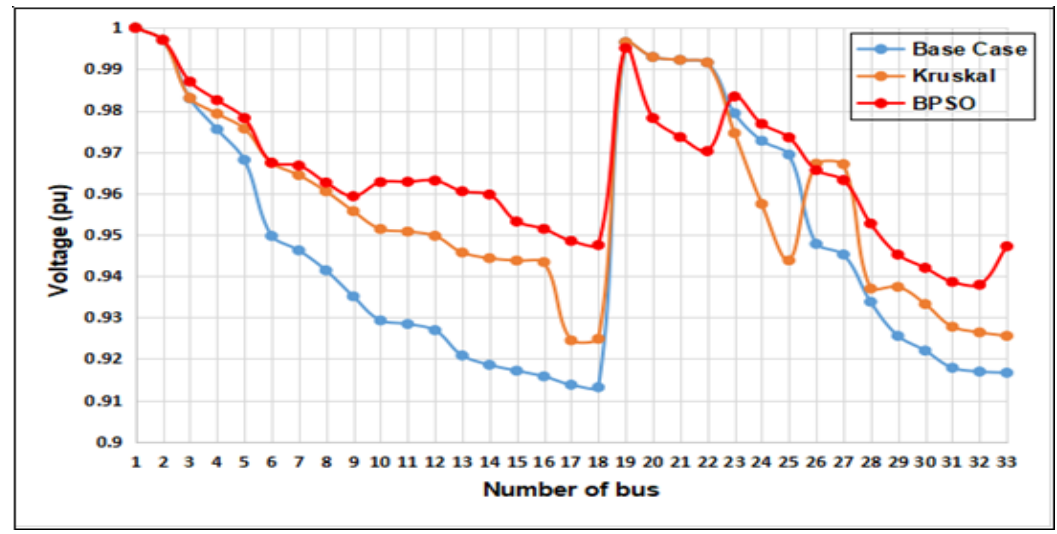

Figure 4. Voltage profile improvement

Table 4 indicates the result of single line outage of S13, S21 and S28 that occurs at a distribution system. In power outage condition, the impedance of the distribution line was increased to indicate that fault happens in that area. The line applied with fault will not operate, hence, making it to function as open switch. The result for Kruskal's algorithm is compared with randomly selected switch. It means that one out of five open switches in Kruskal's algorithm is selected randomly to observe the power loss between those cases. The result shows that the power loss for Kruskal's algorithm is less compared to randomly selected switches.

Table 4. Result for Single Line Outage

\begin{tabular}{|c|c|c|c|c|c|c|c|}
\hline \multirow{2}{*}{ Outage line } & \multirow{2}{*}{ Method } & \multirow{2}{*}{\multicolumn{4}{|c|}{ Switches }} & \multicolumn{2}{|c|}{ Power loss } \\
\hline & & & & & & MW & MVar \\
\hline \multirow{2}{*}{ S13 } & Kruskal & S27 & S33 & S34 & S35 & 0.1971 & 0.1377 \\
\hline & Randomly selected switches & S25 & S33 & S34 & S35 & 0.2072 & 0.1459 \\
\hline \multirow{2}{*}{$\mathrm{S} 21$} & Kruskal & S16 & S27 & S33 & S34 & 0.1872 & 0.1275 \\
\hline & Randomly selected switches & S10 & S27 & S33 & S34 & 0.2466 & 0.1788 \\
\hline \multirow{2}{*}{ S28 } & Kruskal & S16 & S33 & S34 & S35 & 0.1757 & 0.1193 \\
\hline & Randomly selected switches & S8 & S33 & S34 & S35 & 0.2415 & 0.1758 \\
\hline
\end{tabular}

Figure 5 shows the comparison of voltage profile between Kruskal's algorithm and randomly selected switches when fault occurred at line 28. The voltage of a power system is stable under normal operating condition. However, the voltage will become unstable when the fault occurs in the system since the voltage drops below the acceptable limit. By using random switches selection, the lowest voltage value can be observed at bus 9 with 0.87 p.u. Meanwhile, by using Kruskal algorithm, the overall voltage profile is within the acceptable limit. This justify that Kruskal's algorithm can perform better than the random selection in restoring the load within the voltage limit. 


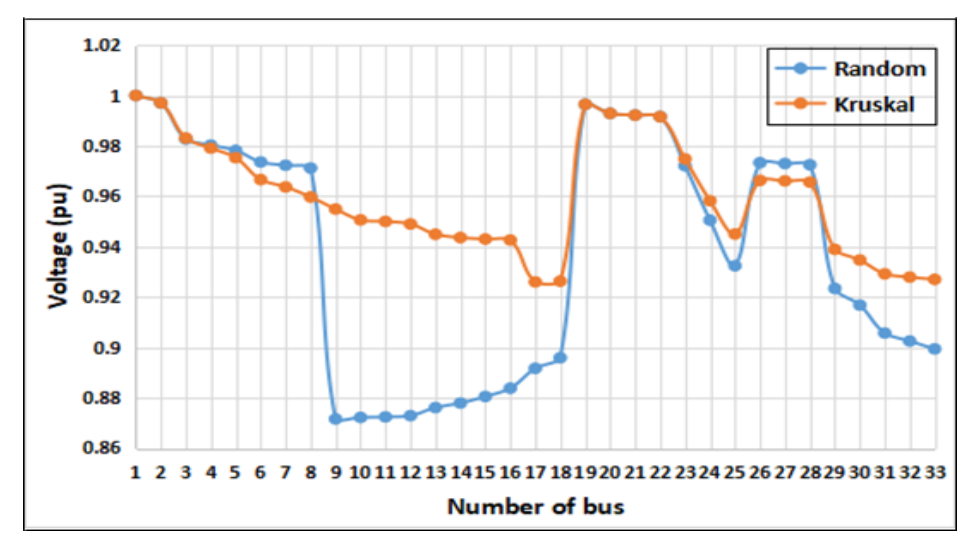

Figure 5. Comparison of voltage during fault at line S28

\section{CONCLUSION}

This paper proposes a power system restoration in radial distribution network based on Kruskal's algorithm. This algorithm determines the minimum flow path for power restoration in the out of service area. The effectiveness of the proposed algorithm has been carried out on IEEE 33-bus system where power is restored based on minimum line weight. From the test results obtained, the presented load restoration scheme is capable of finding the minimal path according to line weight. In addition, Kruskal's algorithm is better compared to Binary Particle Swarm Optimization (BPSO) in terms of time duration.

\section{ACKNOWLEDGEMENTS}

This work was supported by Ministry of Higher Education and Universiti Teknologi MARA, Malaysia under FRGS research grant (Grant Code: 600-IRMI/FRGS 5/3 (090/2019)).

\section{REFERENCES}

[1] Y. Xue and S. Xiao, "Generalized congestion of power systems: insights from the massive blackouts in India," $J$. Mod. Power Syst. Clean Energy, vol. 1, no. 2, pp. 91-100, 2013.

[2] Wang, F., Xiao, X., Sun, Q., Chen, S., Fan, J., "Service restoration for distribution network with DGs based on stochastic response surface method", International Journal of Electrical Power and Energy Systems, 107, pp. 557-568, 2019.

[3] Escalera, A., Prodanović, M., Castronuovo, E., "Analytical methodology for reliability assessment of distribution networks with energy storage in islanded and emergency-tie restoration modes," International Journal of Electrical Power and Energy Systems, 107, pp. 735-744, 2019.

[4] Zetty Adibah Kamaruzzaman, Azah Mohamed, Ramizi Mohamed, "Optimal placement of grid-connected photovoltaic generators in a power system for voltage stability enhancement”, Indonesian Journal of Electrical Engineering and Computer Science (IJEECS), Vol. 13, No. 1, pp 339-346, January 2019.

[5] Kleinberg, M.R., Miu, K., Chiang, H., "Improving service restoration of power distribution systems through load curtailment of in-service customers", IEEE Transactions on Power Systems, 26 (3), art. No. 5638627, pp. 1110-1117 2011.

[6] Huang, C., "Multiobjective service restoration of distribution systems using fuzzy cause-effect networks", IEEE Transactions on Power Systems, 18 (2), pp. 867-874, 2003.

[7] Marques, L.T., Delbem, "Restoration with Prioritization of Customers and Switches and Determination of Switching Sequence", IEEE Transactions on Smart Grid, 9 (3), pp. 2359-2370, 2018.

[8] Kumar, Y., Das, B., Sharma, J, "Multiobjective, multiconstraint service restoration of electric power distribution system with priority customers", IEEE Transactions on Power Delivery, 23 (1), pp. 261-270, 2018.

[9] P. Ravi Babu, Molughu Srivani, "AACO technique for solving multiobjectives in electrical distribution system", Indonesian Journal of Electrical Engineering and Computer Science (IJEECS), Vol. 14, No. 3, pp. 1076-1086, June 2019.

[10] A.V. Sudhakara Reddy, M.Damodar Reddy, M.Satish Kumar Reddy, "Network reconfiguration of distribution system for loss reduction using GWO algorithm", International Journal of Electrical and Computer Engineering (IJECE), Vol.7, No.6, pp.3226-3234, December 2017.

[11] Zeba Khan, Mahfooz Alam, Raza Abbas Haidri, "effective load balance scheduling schemes for heterogeneous distribution system", International Journal of Electrical and Computer Engineering (IJECE), Vol.7, No.5, pp.2757-2765, October 2017.

[12] Zhou, Q., Xie, H., Zheng, B., Liao, R., Wang, S., Rao, J., "Hybrid algorithm based coordination between 
distribution network fault reconfiguration and islanding operation”, Dianwang Jishu/Power System Technology, 39 (1), pp. 136-142, 2015.

[13] T. S. and K. Srinivas, "Prims's Algorithm for Loss Minimization and Service Restoration in Distribution Networks," Int. J. Electr. Comput. Eng., vol. Vol 2, no. No 1, pp. 43-62, 2010.

[14] H. S. S. Yu et al., "Distribution System Service Restoration Using A Heuristic Search Approach," IEEE Trans. Power Deliv., vol. 7, no. 2, pp. 734-740

[15] M. Mosbah, S. Arif, R. D. Mohammedi, and A. Hellal, "Optimum dynamic distribution network reconfiguration using minimum spanning tree algorithm,” 2017 5th Int. Conf. Electr. Eng. - Boumerdes, pp. 1-6, 2017.

[16] T. D. Sudhakar, N. S. Vadivoo, S. M. R. Slochanal, and S. Ravichandran, "Supply restoration in distribution networks using Dijkstra's algorithm," Power Syst. Technol. 2004. PowerCon 2004. 2004 Int. Conf., vol. 1, no. November, p. 640-645 Vol.1, 2004.

[17] T. D. Sudhakar and K. N. Srinivas, "Power system reconfiguration based on Prim's algorithm," 2011 1st Int. Conf. Electr. Energy Syst. ICEES 2011, no. i, pp. 12-20, 2011.

[18] P. Ravibabu, K. Venkatesh, and C. S. Kumar, "Implementation of genetic algorithm for optimal network reconfiguration in distribution systems for load balancing," 2008 IEEE Reg. 8 Int. Conf. Comput. Technol. Electr. Electron. Eng., pp. 124-128, 2008.

[19] S. Rai and S. Sharma, "Determining minimum spanning tree in an undirected weighted graph," Conf. Proceeding 2015 Int. Conf. Adv. Comput. Eng. Appl. ICACEA 2015, pp. 637-642,2015.

[20] L. W. Oliveira et al., "Optimal restoration of power distribution system through particle swarm optimization," 2015 IEEE Eindhoven PowerTech, PowerTech 2015, 2015.

[21] E. Engineering, "Power System Restoration Based on Kruskal's Algorithm,” Energy, pp. 281-287, 2011.

[22] D. Pavana and M. T. Triveni, "Power System Restoration in Distribution Network Through Reconfiguration Using Mst- Kruskal 'S Algorithm,” IJRET Int. J. Res. Eng. Technol., pp. 295-299, 2015.

[23] B. Chen, F. Wei, J. Pan, and Y. Xia, "The minimum spanning trees of tRNA sequences based on Prim's algorithm," 5th Int. Conf. Nat. Comput. ICNC 2009, vol. 6, pp. 176-179, 2009.

[24] H. Ahmadi and J. R. Martí, "Minimum-loss network reconfiguration: A minimum spanning tree problem," Sustain. Energy, Grids Networks, vol. 1, pp. 1-9, 2015.

[25] Shridevi Narasannavar, Rashmi Kannur, S B Karajgi, "Restoration of Power Supply in a Multiple Feeder Distribution Network using Dijkstra's Algorithm," International Journal of Current Engineering and Technology, vol. 4, no. 3, pp. 1972-1976, 2014.

\section{BIOGRAPHIES OF AUTHORS}

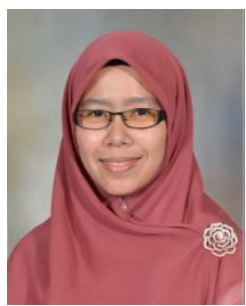

Hasmaini Mohamad received the B.Eng., M.Eng. and Ph.D. degrees from the University of Malaya, Malaysia in 1999, 2004, and 2012 respectively. Currently she is a senior lecturer and professional engineer in the Universiti Teknologi MARA (UiTM), Malaysia. Her major research interest includes islanding operation of distributed generation, load sharing technique and load shedding scheme

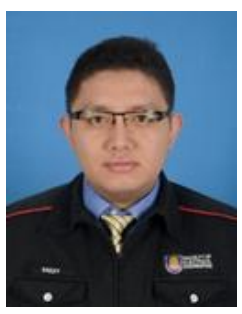

Wan Iqmal Faezy received his Bachelor in Electrical Engineering from Universiti Teknologi MARA in 2018. He is currently working toward Masters Degree at the same university. His research interest includes smart grid technologies, electric vehicles, power system stability and artificial intelligent techniques

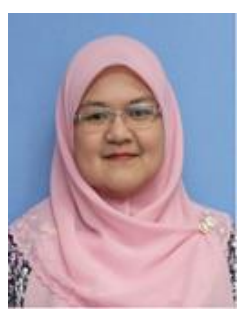

Nur Ashida Salim received her Ph.D in Electrical Engineering from Universiti Teknologi MARA Malaysia in 2015 and MEng (Power System \& Electrical Energy) from Universiti Malaya in 2006. She is currently a lecturer at Universiti Teknologi MARA, MALAYSIA. Her research interests includes power system reliability, power system planning, power system stability and power system risk assessment 


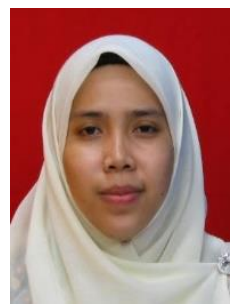

Shahrani Shahbudin received B.Eng. (Hons) degree from the University of Malaya, Kuala Lumpur in 1999. Master and Phd in 2004 and 2014 from Universiti Kebangsaan Malaysia respectively. She is currently working as a senior lecturer at the Centre for Computer Engineering Studies, Faculty of Electrical Engineering, Universiti Teknologi MARA (UiTM) Shah Alam and member of MBOT, IEEE, IEM and BEM organization. Her main research interests include machine learning, deep learning, intelligent system, pattern classification and IoT for classification and visualization.

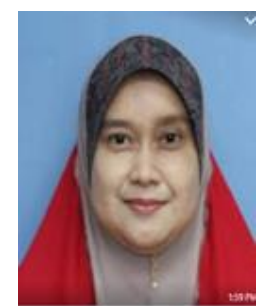

Zuhaila Mat Yasin graduated from Universiti Sains Malaysia with honours degree in Electrical and Electronics Engineering in 1998. She obtained her MSc degree in 2008 and $\mathrm{PhD}$ degree in 2015 from Universiti Teknologi MARA. Her research interest includes power system operation, optimization, distributed generation, Artificial Intelligence and smart grid system. 